\title{
GUIA PRÁTICA DAS ESCALAS WECHSLER
}

Resenha

Paula Isabela Barbosa - Centro Universitário Salesiano - Unisal Americana

Paula Isabela Barbosa

Estudante de gradução de psicologia Centro Universitário Salesiano - Unisal Americana

\section{Correspondencia}

Av. de Cillo, 3500 - Parque Novo Mundo, Americana - SP, 13467-600, Brasil

Teléfono: +55 19 3471-9700 
O livro “Guia Prático das Escalas Wechsler, apresenta as Escalas WISC-IV, WAISIII e WASI, e tem como proposta facilitar a utilização e análise dos mesmos, orientando sobre seus principais aspectos. Baseia-se em extensas pesquisas acerca da cognição e da prática clínica em avaliações, indicando possibilidades que visam explorar ao máximo os indicadores dos protocolos, para uma melhor compreensão acerca do indivíduo avaliado, auxiliando na prática profissional e no processo de avaliação psicológica.

O guia toma como base o Modelo Cattell-Horn-Carroll (CHC) das Habilidades Cognitivas, e apresenta no segundo capítulo uma breve explanação dele, com foco em seus principais aspectos. Tal Modelo, resulta de diversas pesquisas de diferentes autores, que objetivavam compreender melhor a inteligência e estudaram sistematicamente tendo como base evidências observáveis de coletas e análise de dados acerca do construto. No Modelo CHC das Habilidades Cognitivas a inteligência é compreendida como uma estrutura hierárquica e multidimensional, contemplando um conjunto de habilidades cognitivas que está organizada em três níveis, chamados de estratos e que são dispostos em uma estrutura de pirâmide. Ao final deste mesmo capítulo, utilizando-se de uma linguagem clara e objetiva são apresentas as definições dos principais fatores que compõe os estratos, proporcionando uma melhor compreensão do modo como as habilidades cognitivas são descritas no Modelo.

Em seguida, o guia traz uma correlação das Escalas com o Modelo, apresentando as provas do WISC-IV, WAIS-III e WASI e descrevendo quais habilidades cognitivas estão envolvidas em cada tarefa que os instrumentos apresentam. Embora as Escalas Wechsler não tenham sido criadas a partir do Modelo $\mathrm{CHC}$, tal correlação é possível pois algumas atualizações nas Escalas foram favorecidas devido à avanços na compreensão dos processos cognitivos que resultaram dos estudos do Modelo CHC. Ao fazer isso, o guia proporciona 
maior clareza do construto avaliado pelos subtestes da ferramenta utilizada e contribui na criação de intervenções mais eficientes.

Os próximos três capítulos são destinados à uma descrição mais detalhada das Escalas Wechsler, o primeiro a ser apresentado é o WISC-IV, sendo este destinado para utilização com crianças de 6 a 16 anos e 11 meses, com objetivo de avaliar a capacidade intelectual das crianças e o processo de resolução de problemas. O guia apresenta e disserta sobre cinco passos que pode auxiliar na análise do protocolo e interpretação dos dados, contribuindo para a compreensão do perfil da criança, são eles: 1. Compreender o construto avaliado; 2. Compreender o construto a partir da ferramenta utilizada; 3. Integrar os resultados de forma dinâmica; 4. Relatar as interpretações relacionadas à queixa; 5. Propor intervenções baseadas nas evidências observadas. Destaca-se que, no segundo passo apresentado, o guia traz a descrição das provas do WISC-IV e seus correlatos no Modelo CHC, elucidando a presença do construto nas tarefas dos subtestes. Nos passos três, quatro e cinco, discorre sobre principais aspectos da análise, interpretação e aplicação prática dos resultados, fornecendo dicas que possam enriquecer o processo de elaboração de laudos e da criação de rotas terapêuticas na intervenção.

A segunda Escala apresentada é o WAIS-III, aplica-se a faixa etária de 16 a 89 anos, e tem finalidade de avaliar a capacidade intelectual de adolescentes, adultos e idosos. Os autores apresentam neste capítulo possibilidades de analisar as pontuações obtidas no instrumento e de interpretação dos índices, baseado em informações do manual e em obras complementares, principalmente o Modelo CHC. As sugestões de interpretação e análises apresentadas no guia foram feitas pensando nas dúvidas frequentes de estudantes e psicólogos, uma vez que os autores do livro partiram do contexto da prática clínica, de supervisões e aulas que ministraram, objetivando auxiliar no processo de correção e 
interpretação do WAIS-III. Por último, é apresentada a Escala WASI, voltado à faixa etária de 6 a 89 anos, procura fornecer uma estimativa rápida do funcionamento intelectual, sendo portanto, indicada para processos de avaliação cognitiva de rastreio ou que dispõem de pouco tempo para a execução.

Sendo assim, fica evidente que o livro cumpre a proposta a qual se faz de ser um guia, uma vez que indica caminhos possíveis na compreensão, interpretação e intervenção em processos de avaliação com o uso das Escalas Wechsler, utilizando como base o Modelo CHC das Habilidades Cognitivas. O guia configura-se como uma ferramenta relevante e pode ser utilizado como material complementar aos manuais, contribuindo para a compreensão do sujeito avaliado, no complexo processo da avaliação psicológica.

\section{Referencia}

Pessotto, F.; Batholomeu, D. (2019). Guia Prática das Escalas Wechsler: Uso e Análise das Escalas WISC-IV, WAIS-III e WASI. São Paulo: Pearson. 